\title{
Phospho-proteomic analysis of mantle cell lymphoma cells suggests a pro-survival role of B-cell receptor signaling
}

\author{
Chiara Pighi • Ting-Lei Gu • Irene Dalai • Stefano Barbi • Claudia Parolini • \\ Anna Bertolaso • Serena Pedron - Alice Parisi • Jianmin Ren • Daniela Cecconi • \\ Marco Chilosi • Fabio Menestrina • Alberto Zamò
}

Accepted: 12 February 2011 / Published online: 11 March 2011

(C) The Author(s) 2011. This article is published with open access at Springerlink.com

\begin{abstract}
Background Mantle cell lymphoma (MCL) is currently an incurable entity, and new therapeutic approaches are needed. We have applied a high-throughput phospho-proteomic technique to MCL cell lines to identify activated pathways and we have then validated our data in both cell lines and tumor tissues. Methods PhosphoScan analysis was performed on MCL cell lines. Results were validated by flow cytometry and western blotting. Functional validation was performed by blocking the most active pathway in MCL cell lines. Results PhosphoScan identified more than 300 tyrosinephosporylated proteins, among which many protein
\end{abstract}

Electronic supplementary material The online version of this article (doi:10.1007/s13402-011-0019-7) contains supplementary material, which is available to authorized users.

C. Pighi $\cdot$ I. Dalai $\cdot$ S. Barbi $\cdot$ C. Parolini $\cdot$ A. Bertolaso $\cdot$

S. Pedron · A. Parisi $\cdot$ M. Chilosi $\cdot$ F. Menestrina $\cdot$ A. Zamò

Department of Pathology and Diagnostics, University of Verona,

P.le Scuro 10,

37134 Verona, Italy

T.-L. Gu $\cdot$ J. Ren

Cell Signaling Technology Inc.,

3 Trask Lane,

Danvers, MA 01923, USA

D. Cecconi

Department of Biotechnology, University of Verona,

Strada Le Grazie 15,

37134 Verona, Italy

\section{A. Zamò $(\square)$}

Dipartimento di Patologia e Diagnostica, Sezione di Anatomia Patologica, Università di Verona - Policlinico G. B. Rossi,

Piazzale L. A. Scuro, 10,

37134 Verona, Italy

e-mail: alberto.zamo@univr.it kinases. The most abundant peptides belonged to proteins connected with B-cell receptor (BCR) signaling. Active BCR signaling was demonstrated by flow cytometry in MCL cells and by western blotting in MCL tumor tissues. Blocking BCR signaling by Syk inhibitor piceatannol induced dose/time-dependent apoptosis in MCL cell lines, as well as several modifications in the phosphorylation status of BCR pathway members and a collapse of cyclin D1 protein levels.

Conclusion Our data support a pro-survival role of BCR signaling in MCL and suggest that this pathway might be a candidate for therapy. Our findings also suggest that Syk activation patterns might be different in MCL compared to other lymphoma subtypes.

Keywords Mantle cell lymphoma Proteomics . PhosphoScan $\cdot$ Syk $\cdot$ Piceatannol $\cdot$ BCR signaling

\section{Introduction}

Mantle cell lymphoma constitutes about $6 \%$ of nonHodgkin lymphoma in the western world [1]. It shows a characteristic clinical behavior with initial response to therapy followed by relapses and death in 3-5 years. Aggressive therapeutic regimens are promising, but to-date MCL is still considered incurable, with the exception of a small group of long-surviving patients. In recent years, many high-throughput techniques have been applied to MCL in order to gain insights into its pathogenesis, and to discover suitable therapeutic targets [2-9]. These studies have clarified a role for increased proliferation and resistance to apoptosis in MCL, involving several signaling pathways. 
A few studies from our group and also from others have attempted the study of MCL from a proteomic point of view [10-18]. Some of these studies were mainly focused on the diagnostic implementation of proteomic techniques [14-16], while other were more focused on the pathogenetic mechanisms [12, 18-20]. These studies have identified single up-regulated proteins in MCL compared to tonsil Bcells [12], or several proteins up-regulated in MCL cell lines compared to FL-derived cell lines followed by network analysis [21]. More recently, a proteomic study focused on the plasma membrane proteome of leukemic MCL and compared it to normal B-cells [19]; this study identified several alterations in the proteome of MCL lipid rafts that might have therapeutic potential. In a previous study we have focused our attention on the phospho-proteome of several MCL cell lines by using immobilized metal affinity chromatography (IMAC) pre-fractionation (a column-based technique that selectively enriches all phospho-proteins by a reversible binding to metal oxydes), followed by 2D-PAGE/ MS [20]. In that study we identified several activated pathways that might reflect the biology of MCL, including the alternative NF-kB pathway, the mTOR pathway and the mitochondrial pathway. In the present work we have used a complementary approach, called PhosphoScan, that involves an immunoprecipitation of peptides by using an antiphosphotyrosine antibody followed by capillary electrophoresis and MS identification of eluted peptides [22]. Compared to IMAC, PhosphoScan should better dissect phosphorylation profiles, specifically identifying tyrosinephosphorylated peptides. This approach has already been successfully used in the phospho-profiling of primary [23] and metastatic [24] lung cancer, in acute leukemia samples [25], in Bcr/Abl positive cell lines [26], AML cell lines [27] and Hodgkin lymphoma cell lines [28]. Since tyrosine phosphorylation regulates the activity of many proteins, the PhosphoScan approach can provide a picture of the most active pathways in the analyzed samples. Moreover, since many kinases are themselves activated by tyrosine phosphorylation, the profile of active kinases is also provided; often these kinases are driving cell proliferation and survival, and are therefore candidate targets for therapy.

In the current work, we used this approach to recognize the most represented activated pathways in MCL cell lines. We then verified the presence of these activated molecules in MCL cell lines and tumor tissues. We subsequently explored the functional role of the most activated pathway in MCL cell lines by inhibition experiments.

\section{Results and discussion}

In the current paper we describe the results obtained from the application of PhosphoScan to MCL cells. This is to our knowledge the first use of this technique in MCL; we report a large amount of data with precise identification of phosphorylation sites for each protein, some of which novel.

2.1 PhosphoScan analysis identifies the tyrosine-activated phosphoproteome of MCL cell lines and identifies B-cell receptor signaling as the most active pathway

PhosphoScan analysis identified 421 unique tyrosinephosphorylated peptides, corresponding to 341 proteins, ranked by overall abundance in Table 1 (for a complete list of peptides and complete MS information see Supplemental Table 1). Interestingly, several identified proteins mapped to cytogenetic loci that have been reported to be altered in MCL [29-31]. Among these, several activated protein kinases were identified (Fig. 1), that are therefore appealing as potential therapeutic targets.

The three most represented phospho-peptides are cyclindependent kinases Cdc2, CDK2 and CDK3. Cdc2 (CDK1) is actually part of the proliferation signature able to predict prognosis in MCL [8] and has also been validated at the immunohistochemical level [32]. CDK2 gains have been detected in MCL in a variable proportion of cases [30, 31, 33], and have been associated with a poor prognosis [33]. $C D K 3$ is less studied compared to other cyclin-dependent kinases, but its locus has also been reported as subject to gains [31, 34]. Its involvement in MCL is a novel finding, although the role of $C D K 3$ as an oncogene has been demonstrated in other models $[35,36]$.

Syk and many other BCR pathway members were then found. Many kinases belonging to this pathway (e.g. Syk, Lyn, Hck, Btk, PKC-delta), were among the most represented phospho-peptides identified by the PhosphoScan approach, and this was confirmed when looking for non-random enrichment of Kyoto Encyclopedia of Genes and Genomes (KEGG) pathways [37] compared to the hypothesis of random distribution. This analysis showed that (using a cutoff value of more than five total peptides), the most enriched pathway was hsa04662:B cell receptor signaling pathway (17.16-fold enrichment) (for complete data see Supplemental Table 2).

Many of the proteins belonging to the most enriched pathways were either present in different pathways (redundant) or are functionally connected. Manual annotation by literature search revealed that several of these, in the topmost part of the ranking, were connected to BCR signaling, even if not present in the canonical KEGG BCR pathway (Table 1 and Fig. 2).

2.2 The presence of active B-cell receptor signaling is validated in MCL cell lines and tissues

To further verify the functional role of BCR signaling in MCL, we analyzed the phosphorylation status of Syk, Lyn, 
Table 1 Top 50 phospho-peptides identified (number of phospho peptides corresponding to the specific protein is reported. For complete list and exact phosphorylation sites, see suppl. Table 1)

\begin{tabular}{|c|c|c|c|c|c|c|}
\hline Protein name & Granta-519 & Jeko-1 & MAVER-1 & Rec-1 & BCR pathway & Kynase \\
\hline $\mathrm{Cdc} 2$ & 17 & 38 & 16 & 26 & & $*$ \\
\hline CDK2 & 10 & 34 & 14 & 18 & & $*$ \\
\hline CDK3 & 10 & 33 & 13 & 17 & & $*$ \\
\hline Syk & 9 & 19 & 24 & 3 & $*$ & $*$ \\
\hline SHIP & 7 & 18 & 10 & 10 & $*$ & \\
\hline PAG & 9 & 14 & 4 & 8 & $*$ & \\
\hline PRP4 & 3 & 19 & 8 & 2 & & $*$ \\
\hline Lyn & 4 & 10 & 9 & 7 & $*$ & $*$ \\
\hline Ig-beta & 0 & 22 & 2 & 0 & $*$ & \\
\hline Hck & 3 & 8 & 5 & 3 & $*$ & $*$ \\
\hline WASP & 2 & 7 & 4 & 3 & $*$ & \\
\hline SHP-1 & 4 & 7 & 4 & 1 & $*$ & \\
\hline Btk & 0 & 11 & 4 & 1 & $*$ & $*$ \\
\hline cofilin 1 & 2 & 7 & 5 & 1 & & \\
\hline SgK223 & 6 & 1 & 4 & 4 & & $*$ \\
\hline LANP-L & 0 & 6 & 5 & 3 & & \\
\hline PKCD & 4 & 3 & 2 & 4 & $*$ & $*$ \\
\hline GCET2 & 5 & 7 & 1 & 0 & $*$ & \\
\hline HSP90B & 5 & 5 & 0 & 2 & & \\
\hline GSK3A & 2 & 3 & 4 & 3 & $*$ & $*$ \\
\hline GSK3B & 2 & 3 & 4 & 3 & $*$ & $*$ \\
\hline p38-alpha & 2 & 3 & 6 & 1 & $*$ & $*$ \\
\hline hnRNP A1 & 5 & 2 & 3 & 1 & & \\
\hline GRF-1 & 1 & 4 & 2 & 4 & & \\
\hline SPTBN1 & 0 & 5 & 4 & 1 & & \\
\hline SPTBN1 iso2 & 0 & 5 & 4 & 1 & & \\
\hline PLCG2 & 2 & 4 & 3 & 0 & $*$ & \\
\hline DYRK1A & 1 & 4 & 3 & 1 & & $*$ \\
\hline Lck & 4 & 2 & 1 & 2 & $*$ & $*$ \\
\hline HSP90A & 2 & 4 & 1 & 1 & & \\
\hline Blk & 2 & 3 & 2 & 1 & $*$ & $*$ \\
\hline IRAP & 1 & 4 & 3 & 0 & & \\
\hline DDX3 & 4 & 3 & 0 & 0 & & \\
\hline PL10 & 4 & 3 & 0 & 0 & & \\
\hline Cbl-b & 1 & 3 & 1 & 1 & $*$ & \\
\hline BCAP & 1 & 4 & 1 & 0 & & \\
\hline Dok3 & 0 & 6 & 0 & 0 & * & \\
\hline ANXA2 & 1 & 2 & 2 & 1 & & \\
\hline VIM & 2 & 2 & 2 & 0 & & \\
\hline L-plastin & 0 & 4 & 2 & 0 & & \\
\hline ENO1 & 0 & 2 & 2 & 2 & & \\
\hline PIK3R1 & 1 & 2 & 2 & 1 & $*$ & $*$ \\
\hline DYRK1B & 1 & 2 & 2 & 1 & & $*$ \\
\hline $\mathrm{Src}$ & 1 & 2 & 1 & 2 & $*$ & $*$ \\
\hline Fyn & 1 & 2 & 1 & 2 & $*$ & $*$ \\
\hline Yes & 1 & 2 & 1 & 2 & & $*$ \\
\hline hnRNP $2 \mathrm{H} 9$ & 2 & 3 & 1 & 0 & & \\
\hline hnRNP U & 2 & 3 & 1 & 0 & & \\
\hline $\mathrm{hnRNP} \mathrm{U}$ iso2 & 2 & 3 & 1 & 0 & & \\
\hline PAI-RBP1 & 2 & 2 & 2 & 0 & & \\
\hline
\end{tabular}




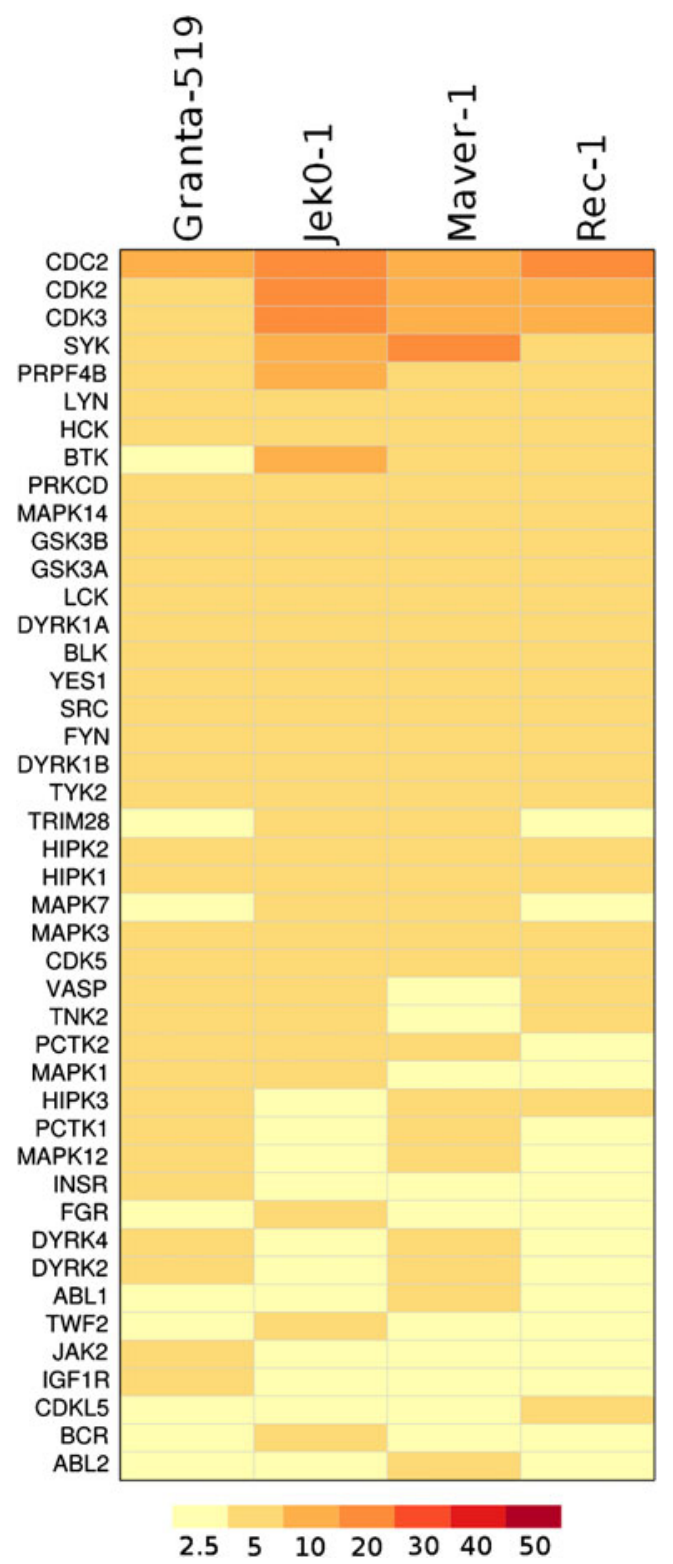

Fig. 1 List of protein kinases identified by the PhosphoScan approach, ranked by overall abundance in the four MCL cell lines analyzed. Color intensity proportional to the number of peptides (see figure for color corresponding to the average number of peptides per cell line)

Btk, Blnk and GSK3alfa/beta in MCL cell lines. Although not present in the top 50 phospho-peptides, Blnk was investigated because it is considered a classical downstream molecule of the BCR pathway. The presence of basal levels of phospho-Syk Y525 and Y323, as well as of phosphoBlnk (Y84) was verified by flow cytometry (Fig. 3). By this technique, we could detect no basal levels of phospho-Syk Y352. In addition basal levels of phospho-Lyn (Y396 and Y507) and also of downstream effectors phospho-Btk (S180) and phospho-GSK3alfa/beta (S9/21) were demonstrated by flow cytometry (Supplemental Figure 1). BCR pathway activation in cell lines is somehow intriguing since it is present in absence of an appropriate antigen stimulation, and is therefore probably self-sustained by tumor cells, either by side-by-side activation or by auto-activation.

In order to verify whether we could find this activation in MCL tumors as well, we resorted to western blotting analysis of phosphorylated forms of BCR pathway members. This analysis showed that the activated forms of Syk (in 5/6 cases, 83\%), Lyn (in 6/6 cases, 100\%), and Blnk (in $6 / 6$ cases, $100 \%$ ) were present also in MCL tumor tissues (Fig. 4), therefore supporting the in vivo role of active BCR signaling; as far as we know, this is the first report of the presence of active (phosphorylated) BCR pathway members in MCL tissues.

The activation of the BCR pathway in MCL has been hypothesized in a previous paper based on cytogenetic and RNA studies [6], but to our knowledge this is the first protein-based and data-driven study that supports this hypothesis. Another proteomic study focusing only on the plasma membrane [19] showed an abnormal association of PKCbeta to the cell membrane in MCL leukemic cells, indirectly supporting an active BCR signaling.

Recent studies have shown the importance of tonic BCR signaling in DLBCL $[38,39]$ and B-CLL [40], with a basal activation of phospho-Syk residue Y352, while Y525 was detected only after BCR cross-linking. The presence of significant basal levels of phospho-Syk Y525 and Y323, with no detectable phospho-Syk Y352 in basal conditions in MCL cells are not concordant with what has been reported in B-CLL and DLBCL [40], and suggest a different pattern of activation of BCR signaling in MCL.

A recent report of a phase $1 / 2$ clinical trial of fostamatinib disodium, the first clinically available oral Syk inhibitor, in patients with recurrent B-cell nonHodgkin lymphoma, showed that only 1 in $9 \mathrm{MCL}$ showed some response [41]. Several explanations might be possible for this low response rate. First, the specificity of this drug for Syk has been recently questioned [39]. Second, relapsed lymphomas might have evolved into BCR-independent clones (such as the cell line Rec-1). Third, since our data support the hypothesis that the activation pattern of Syk in MCL is different from B-CLL and DLBCL, it is possible that this phenomenon influences the response to fostamatinib.

\subsection{Inhibition of Syk induces apoptosis in MCL cell lines}

Since the proteins belonging to the BCR signaling pathway were shown to be active, we tested the effect of the blockade of this pathway on MCL cells. For this purpose, Syk activity was inhibited by a widely used inhibitor, piceatannol [42-45], a natural stilbene also resulting from the hepatic metabolism of resveratrol, a compound found to 
Table 2 Antibodies used in the study

\begin{tabular}{|c|c|c|c|c|}
\hline Primary antibody & Clone & Source & Dilution & Use \\
\hline Bax & Polyclonal & Cell Signaling & $1: 1000$ & Western blotting \\
\hline Bcl-xL & $54 \mathrm{H} 6$ & Cell Signaling & $1: 1000$ & Western blotting \\
\hline Bcl-2 & 124 & DakoCytomation & $1: 4000$ & Western blotting \\
\hline Caspase 9 & Polyclonal & Cell Signaling & $1: 1000$ & Western blotting \\
\hline Cyclin D1 & SP4 & LabVision & $1: 1000$ & Western blotting \\
\hline $\mathrm{p} 21$ & SX118 & DakoCytomation & $1: 200$ & Western blotting \\
\hline p27 & SX53G8 & DakoCytomation & $1: 200$ & Western blotting \\
\hline p53 & DO-7 & Novocastra & $1: 500$ & Western blotting \\
\hline Syk & Polyclonal & Cell Signaling & $1: 1000$ & Western blotting \\
\hline P-Syk (Y525/526) & $\mathrm{C} 87 \mathrm{C} 1$ & Cell Signaling & $1: 200$ & Western blotting \\
\hline Stat3 & $124 \mathrm{H} 6$ & Cell Signaling & $1: 4000$ & Western blotting \\
\hline P-Stat3(Y705) & D3A7 & Cell Signaling & $1: 500$ & Western blotting \\
\hline PE-P-Syk (Y352) & 17A/P-ZAP70 & BD Biosciences & $1: 100$ & Flow cytometry \\
\hline P-Syk (Y525/526) & Polyclonal & Cell Signaling & $1: 100$ & Flow cytometry/immunofluorescence \\
\hline P-Syk (Y323) & EP573Y & Abcam & $1: 100$ & Flow cytometry \\
\hline P-BLNK (Y84) & J117-1278 & BD Biosciences & $1: 100 / 1: 1000$ & Flow cytometry/western blotting \\
\hline P-Btk (S180) & $3 \mathrm{D} 3$ & Cell Signaling & $1: 100$ & Flow cytometry \\
\hline P-Lyn (Y507) & Polyclonal & Cell Signaling & $1: 100$ & Flow cytometry \\
\hline P-Lyn (Y396) & EP503Y & Abcam & $1: 100 / 1: 200$ & Flow cytometry/western blotting \\
\hline $\mathrm{P}-\mathrm{GSK} 3 \alpha / \beta(\mathrm{S} 9 / 21)$ & $37 \mathrm{~F} 11$ & Cell Signaling & $1: 100$ & Flow cytometry \\
\hline
\end{tabular}

be pro-apoptotic for the MCL cell line Jeko-1 [11]. The Rec-1 cell line showed a marked hypersensitivity to DMSO, and it was deemed unfit for further experimental work, which was conducted on less sensitive cell lines.

Piceatannol induced apoptosis in MCL cell lines Jeko-1, UPN-1, Mino, Maver-1 and Granta-519, as evidenced by Annexin V staining, with a LD50 varying from $9.50 \mu \mathrm{M}$ to $28.91 \mu \mathrm{M}$ at $24 \mathrm{~h}$ and $5.51 \mu \mathrm{M}$ and $23.54 \mu \mathrm{M}$ at $48 \mathrm{~h}$ (Supplemental Table 3 and Fig. 5).

Interestingly, Jeko-1, which is very sensitive to piceatannol, also shows the highest number of phospho-peptides belonging to the BCR pathway (Supplemental Table 4).

Apoptosis was dose and time dependent being visible after $4 \mathrm{~h}$ of treatment in Jeko-1, but only after $16 \mathrm{~h}$ in MAVER-1 (data not shown).

\subsection{Inhibition of Syk down-regulates Cyclin D1 protein levels}

Cyclin D1 protein levels were massively down-regulated in treated cells, as densitometric analysis showed a drop by 85 to $90 \%$ compared to untreated cells (Supplemental Figure 2). The corresponding CCND1 mRNA was downregulated after piceatannol treatment, showing $22 \%$ to $71 \%$ decrease (after normalization) in five tested cell lines (Supplemental Figure 3). This decrease was however significant only in three cell lines, namely UPN-1 (54\% decrease; $p=0.047)$, Granta-519 ( $71 \%$ decrease; $p=0.0078)$ and MAVER-1 (69\% decrease; $p=0.008)$.
This finding is interesting, considering that the CCND1 gene is translocated under the control of a strong enhancer such as the Ig $\mu$ enhancer. A hypothetical scenario could be hypothesized in which BCR signaling and CCND1 gene transcription are connected, possibly via Syk. Cyclin D1 has been shown to be a Syk target gene in breast cancer and other cells [46]. It is possible that $C C N D 1$ gene transcription is directly repressed by Syk, in accordance to the fact that normal B cells show very low levels of this protein and at the same time nuclear localization of Syk. As previously stated, in support of this hypothesis Syk acts as a transcriptional repressor of the CCND1 gene in breast carcinoma cells, and this activity is necessary for its tumorsuppressor function [46]. One hypothesis is that in MCL cells Syk might act via Stat3, a known CCND1 gene transcription inducer, as suggested by a recent publication [47]. In support of this hypothesis, the phosphorylation of Stat 3 was reduced by piceatannol in MCL cell lines (Supplemental Figure 4), while total Stat3 was reduced in Jeko-1 and UPN-1, but not significantly in Maver-1 and Granta-519. According to these data, while the phosphorylation of Stat 3 was reduced in all cell lines, the total level is reduced only in sensitive ones. Several publications support a role for Stat3 in the pathogenesis of MCL [48-52].

According to our data the down-regulation of CCND1 mRNA cannot explain the whole picture, since it was significant only in three cell lines after normalization using an unrelated transcript. An increase in Cyclin D1 degrada- 


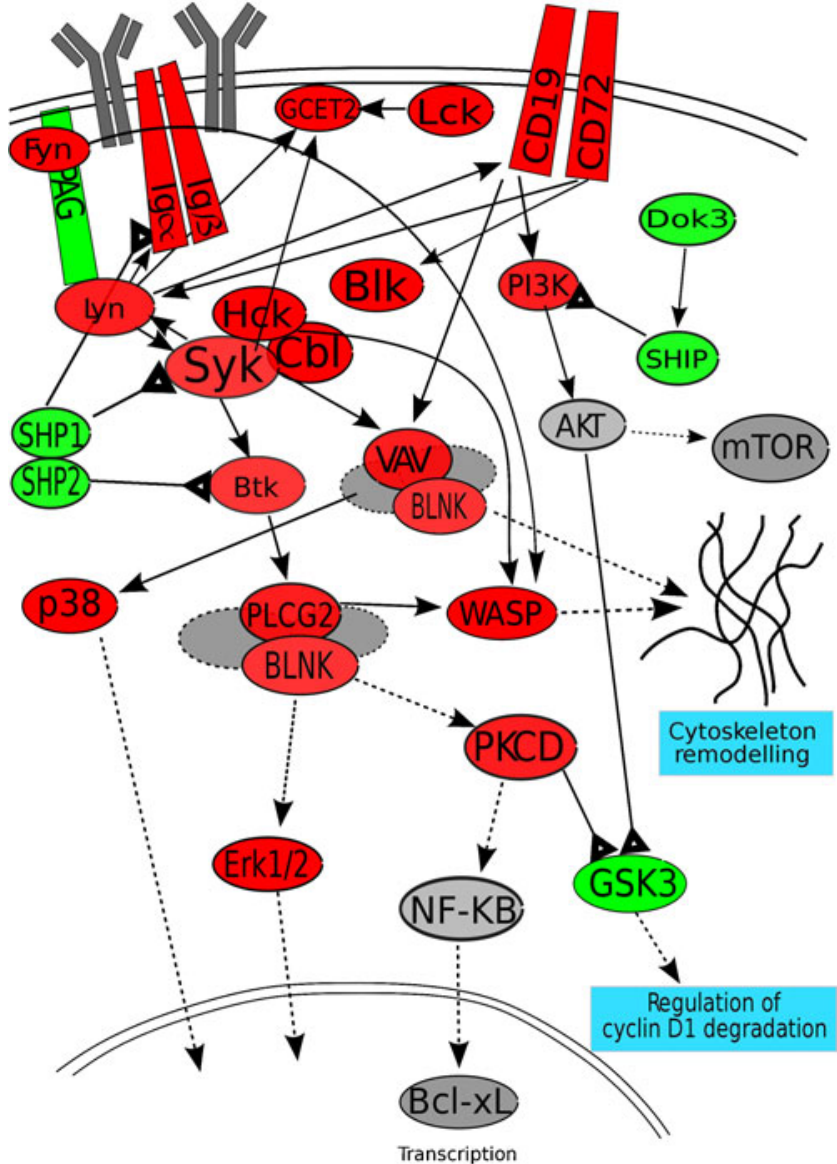

Fig. 2 Simplified diagram showing some of the identified BCR pathway members. In red, activating members; in green, inhibiting members; for some members the precise final effect is not clear; in grey, other proteins known to be present but not identified. Full arrows: direct interaction/activation; dotted arrows: indirect interaction/activation. Data derived from Kyoto Encyclopedia of Genes and Genomes (KEGG) pathway [37] and from published literature. KEGG is a widely used annotated database of pathways, ligands and genes (http://www.genome.jp/kegg/)

tion is another possible explanation, and might operate alongside transcription repression. In support of this complementary hypothesis is the reduction of GSK3 phosphorylation on negative regulatory serine residues, which increases its kinase activity with subsequent phosphorylation and degradation of Cyclin D1 [53].

SYK mRNA was significantly down-regulated by piceatannol treatment in UPN-1 and MAVER-1 (59\% and 75\% reduction; $p=0.047$ and $p=0.01$ respectively). It was also reduced in Granta-519, but the values did not reach statistical significance $(49 \%$ reduction; $p=0.11)$. SYK mRNA was increased after treatment in Jeko-1 and Mino (by $7 \%$ and $40 \%$ respectively) although values were not statistically significant ( $p=0.8$ and $p=0.32$ respectively). Modifications of mRNA levels of SYK and CCND1 showed a good correlation with an $r=0.88$ (Supplemental Figure 3).
2.5 Piceatannol-induced apoptosis involves the activation of the intrinsic pathway, and is accompanied by the modification of several regulators of cell cycle and apoptosis

Apoptosis was triggered trough the intrinsic pathway, involving Caspase 9 cleavage, as shown by western blotting experiments. Cleaved Caspase 8 levels were actually lower in the treated samples than in the untreated ones (not shown). Several apoptosis (Bcl-2, Bcl-xL, Bax, p53, p21), cell-cycle related (p53, p21, p27) molecules were investigated by western blotting. All investigated proteins showed the same behavior in all cell lines with the exception of Bax (Supplemental Figure 5). In detail, p53 levels were increased after treatment (Jeko-1 resulted completely p53-negative due to the presence of a truncating mutation, while other cell lines with the exception of Granta-519 bear a missense mutation [54]); p21 was strongly down-regulated; p27 was cleaved with a decrease of the $27 \mathrm{kDa}$ isoform and increase of the $23 \mathrm{KDa}$ isoform; $\mathrm{Bcl}-2$ was slightly increased, $\mathrm{Bcl}-\mathrm{xL}$ was decreased, while Bax was increased in Jeko-1 and decreased in other cell lines. The mechanism inducing the increase of Bax (a pro-apoptotic Bcl-2 family member) in Jeko-1 is not clear, but this phenomenon might indicate a more pronounced perturbation of mitochondrial outer membrane potential [55]. The only clear-cut genomic abnormality that might suggest a stronger Syk-dependance of Jeko-1 is the presence of the amplification of the SYK locus [6], although this cell line also bears a peculiar missense mutation of TP53 (in addition to a deletion of the other allele) that causes a premature stop codon with degradation of its mRNA [5], and at variance with other cell lines shows no p53 at all; this condition might cause an abnormal regulation of $B A X$, that is a known p53 target gene [56].

2.6 Piceatannol induces complex modifications of the Syk phosphorylation pattern and alterations of downstream effectors of the B-cell receptor pathway

To verify the effects of piceatannol on the pattern of phosphorylation of Syk and other BCR pathway members, we resorted to flow cytometry using phospho-specific antibodies. These experiments showed that piceatannol induced a marked decrease in phospho-Syk tyrosine residues Y525 and Y323, while unexpectedly the levels of Y352, which were almost negative in basal conditions, increased after treatment (Fig. 6). This residue resides in the linker region of Syk, in a stretch that is essential for nuclear localization, since a mutant lacking residues $332-359$ was unable to enter the nucleus, as reported by a previous article [57]. These modifications were detectable after $6 \mathrm{~h}$ of treatment, but not after two (data not shown). As previously stated, B-CLL and DLBCL cells show a basal activation of 
Fig. 3 Analysis of basal levels of phosphorylated Syk and Blnk residues by flow cytometry. In grey, isotypic control; in red, basal levels. On the $\mathrm{X}$ axis, arbitrary fluorescence units (log scale); on the $\mathrm{Y}$ axis, cell count

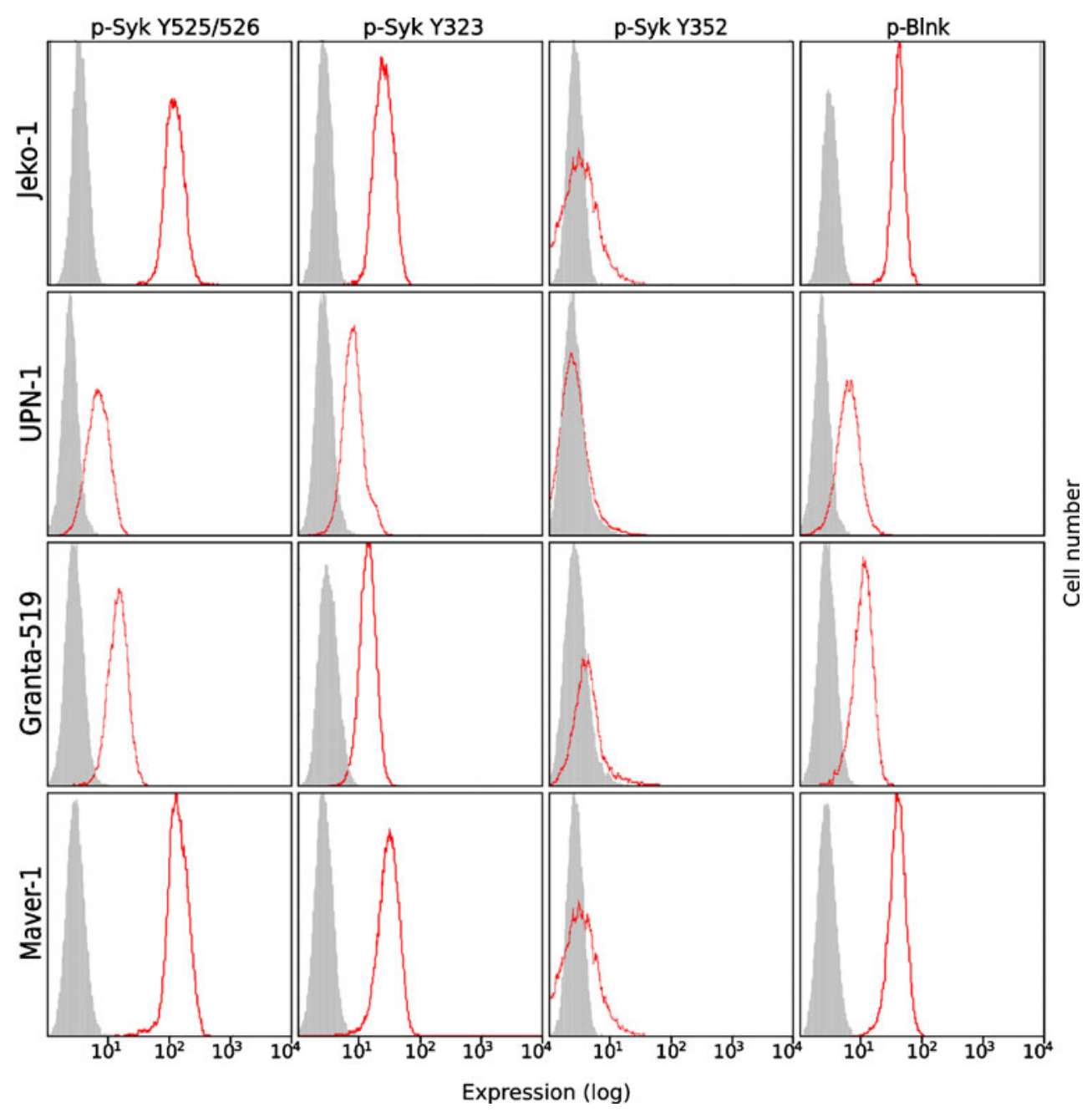

Syk Y352, but no information is available for comparison about how this phosphorylation might be changed by Syk inhibition.

The levels of the downstream effectors phospho-Blnk and phospho-Btk were also reduced by piceatannol treatment in Jeko-1 and to a lesser degree in MAVER-1 cells (Supplemental Figure 6).

To obtain independent information about the modifications of phospho-Syk after treatment, we used immunofluorescence microscopy. These experiments showed that in basal conditions phospho-Syk (Y525) is present in all cell lines tested, and is apparently confined to the cytoplasmic compartment of MCL cell lines (with the exception of Granta-519, that showed also a partial nuclear localization). After piceatannol treatment phospho-Syk (Y525) was down-regulated in the cytoplasm, but its presence could be demonstrated in the nucleus of MCL cell lines (Jeko-1, UPN-1, Mino, Granta-519, MAVER-1) (Fig. 7). This finding is in accordance with the reduction of phosphoSyk (Y525) detected by antibodies used in flow cytometry
Fig. 4 Western blotting analysis of MCL tissues. The presence of phospho-Syk (Y525), phosphoLyn (Y396) and phospho-Blnk (Y84) is shown in six MCL tumor tissues. Cases 1, 2, 5 and 6 were classical MCL, while cases 3 and 4 were blastoid variants

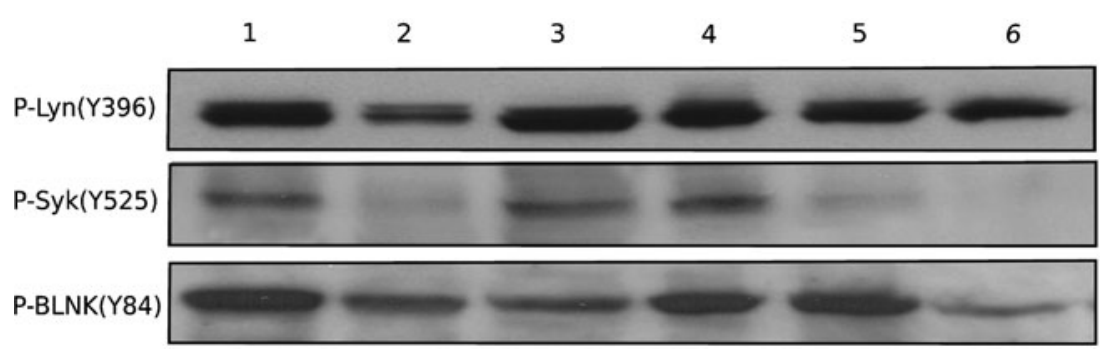


Fig. 5 Induction of apoptosis in MCL cell lines. Upper panel shows the percentage of live cells ( $\mathrm{Y}$ axis) in function of the piceatannol concentration $(\mathrm{X}$ axis) at $24 \mathrm{~h}$. Lower panel shows the same variables at $48 \mathrm{~h}$ of treatment. Annexin V staining was used to discriminate apoptotic cells
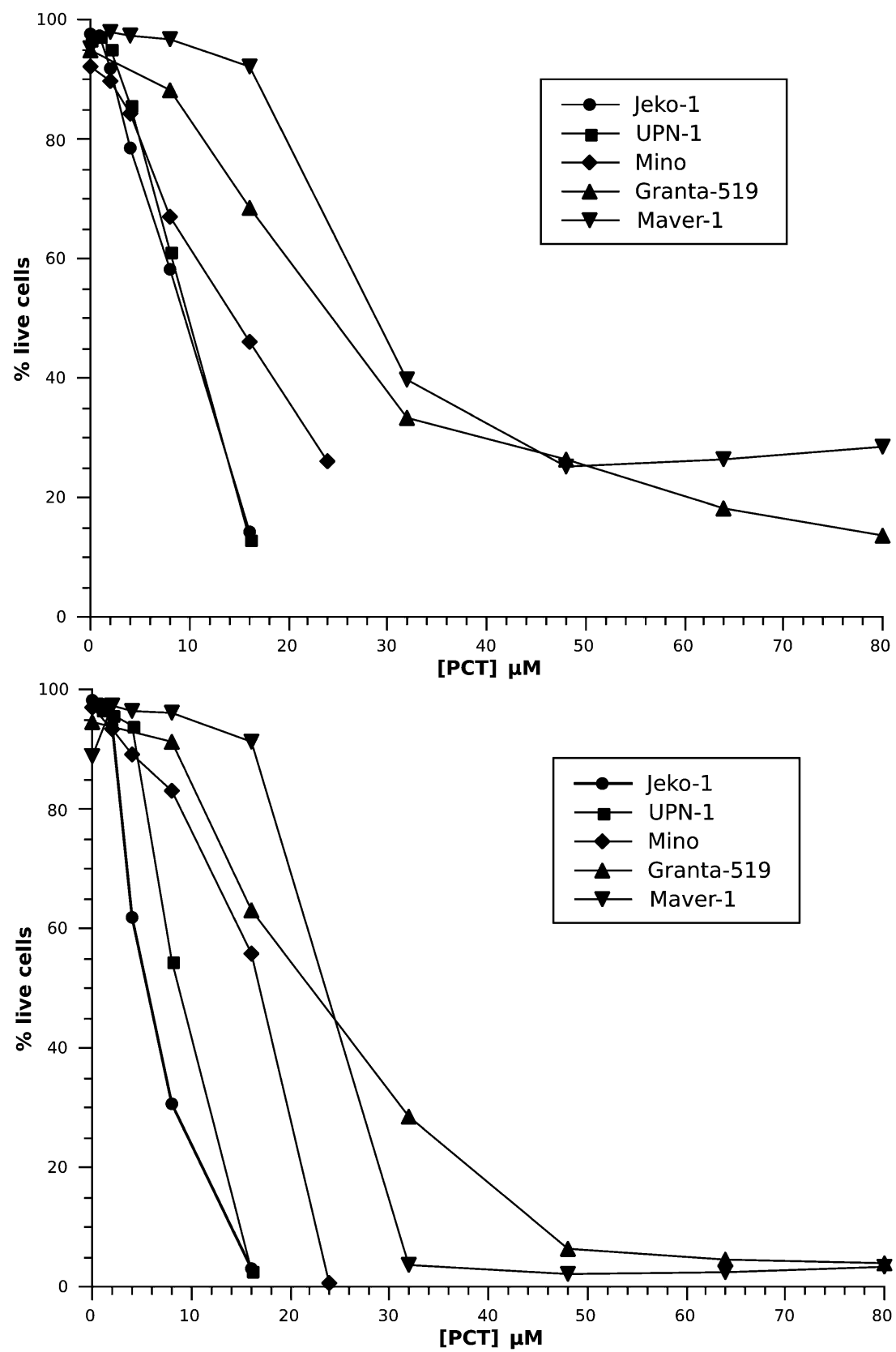

experiments, which were able to enter the cytoplasm but not the nucleus in our experimental conditions.

One possible hypothesis to explain this phenomenon is the fact that Syk has two known splice variants, of which only the longest is able to enter the nucleus [58]. Western blotting experiments in the five MCL cell lines Jeko-1, Granta-519, MAVER-1, UPN-1 and Rec-1 showed that only one band was identifiable in the expected molecular weight range. A proteolytic $36 \mathrm{kDa}$ isoform of Syk was also detected (data not shown), although the significance of this isoform described in erythrocytes [59], is still not clear in our cells, because it might be either a true functional variant or an experimental artifact. The absence of the shortest splice variant of Syk was also demonstrated by isoform-specific SYK RT-PCR experiments (Supplemental Figure 7). This was confirmed using two amplicons of different length as previously described [58]. The nuclear exclusion phenomenon therefore is probably not related to Syk differential splicing, but more probably to functional modifications of the protein, such as phosphorylation.

\section{Conclusions}

Our study has identified a large number of phosphorylated proteins and several activated pathways in MCL cells, 
Fig. 6 Modification of Syk phosphorylation profile following piceatannol treatment. After treatment, phosphorylation of residues Y525 and Y323 is reduced, while that of residue Y352 is increased. Red, untreated cells; blue, treated cells; solid grey, isotypic control

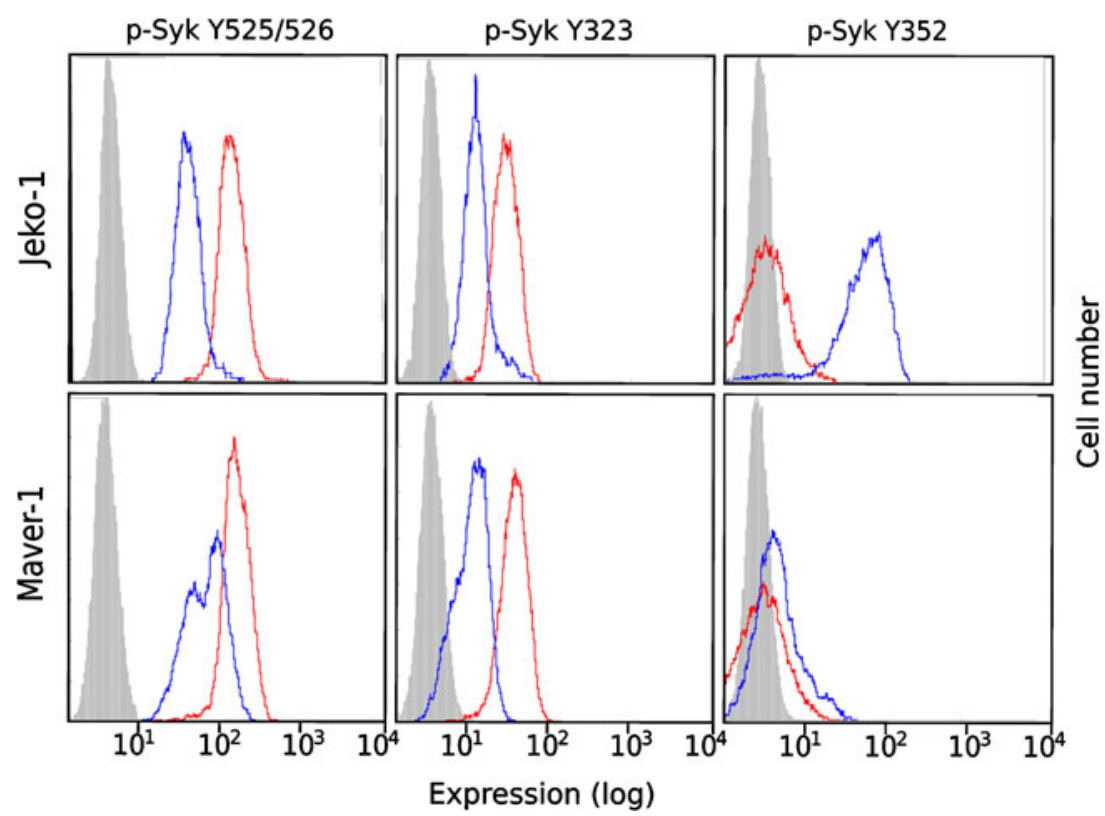

which deserve a more thorough investigation by functional validation experiments. Our experimental data suggest that active BCR signaling is present in MCL cell lines and tumors, and that it plays a role in the survival of MCL cells; Syk is possibly one of the key molecules in this event, and it might have a double-face role in the cytoplasmic and nuclear compartments.

Our data also suggest that piceatannol, resveratrol or their analogues could represent a therapeutic option for patients with MCL if in vitro data will be confirmed in vivo.

\section{Methods}

Cell lines MCL cell lines Jeko-1, Granta-519 and Rec-1 were purchased from DSMZ (Braunschweig, Germany). Cell line MAVER-1 was developed in our laboratory [60]. Cell line Mino was obtained from ATCC (Manassas, VA, USA). UPN-1 cells were kindly provided by Dr. Elias Campo (Barcelona, Spain). Due to over-sensitivity to DMSO-induced apoptosis, Rec-1 cells were not used for apoptosis-induction assays.

Tumor samples Tumor samples were collected from the archives of the Department of Pathology and Diagnostics of the University of Verona. Informed consent had been collected for all patients and procedures were carried out according to the ethical guidelines of the University Hospital of Verona with the approval of an ethics committee, in compliance with the Helsinky Declaration.
PhosphoScan analysis PhosphoScan analysis was performed as previously described [23] on MCL cell lines MAVER-1, Granta-519, Jeko-1, and Rec-1.

The phospho-proteins identified using this analysis were categorized into KEGG Pathways using the DAVID Ease web framework [61]. For P-value and fold enrichment calculation the complete list of human genes was considered as a background. The calculation was repeated for lists obtained by selecting genes above the abundance cut-offs of 3,4 and 5 .

Illustrations were produced using the $\mathrm{R}$ statistical software package (http://www.r-project.org).

Flow cytometry Flow cytometric analysis of several tyrosine-phosphorylated forms of Syk (Y323, Y352 and Y525) and downstream target phospho-BLNK was performed as previously described [38] using antibodies shown in Table 2. All experiments were performed in triplicate.

RNA isolation and cDNA synthesis RNA isolation was performed using the Allprep DNA/RNA/Protein Mini Kit (Qiagen GmbH, Hilden, Germany), and RNA quality was assessed by using an Agilent 2100 Bioanalyzer (Agilent Technologies, Palo Alto, CA, USA) and RNA 6000 Nano chips (Agilent Technologies). Each cDNA was synthesized from $1 \mu \mathrm{g}$ total RNA using random primers and the Superscript III First-strand synthesis system (Invitrogen, Carlsbad, CA, USA) according to the manufacturer's instructions.

$R T-P C R$ The analysis of $S Y K$ isoforms was performed as previously described [58]. Reaction products were ana- 

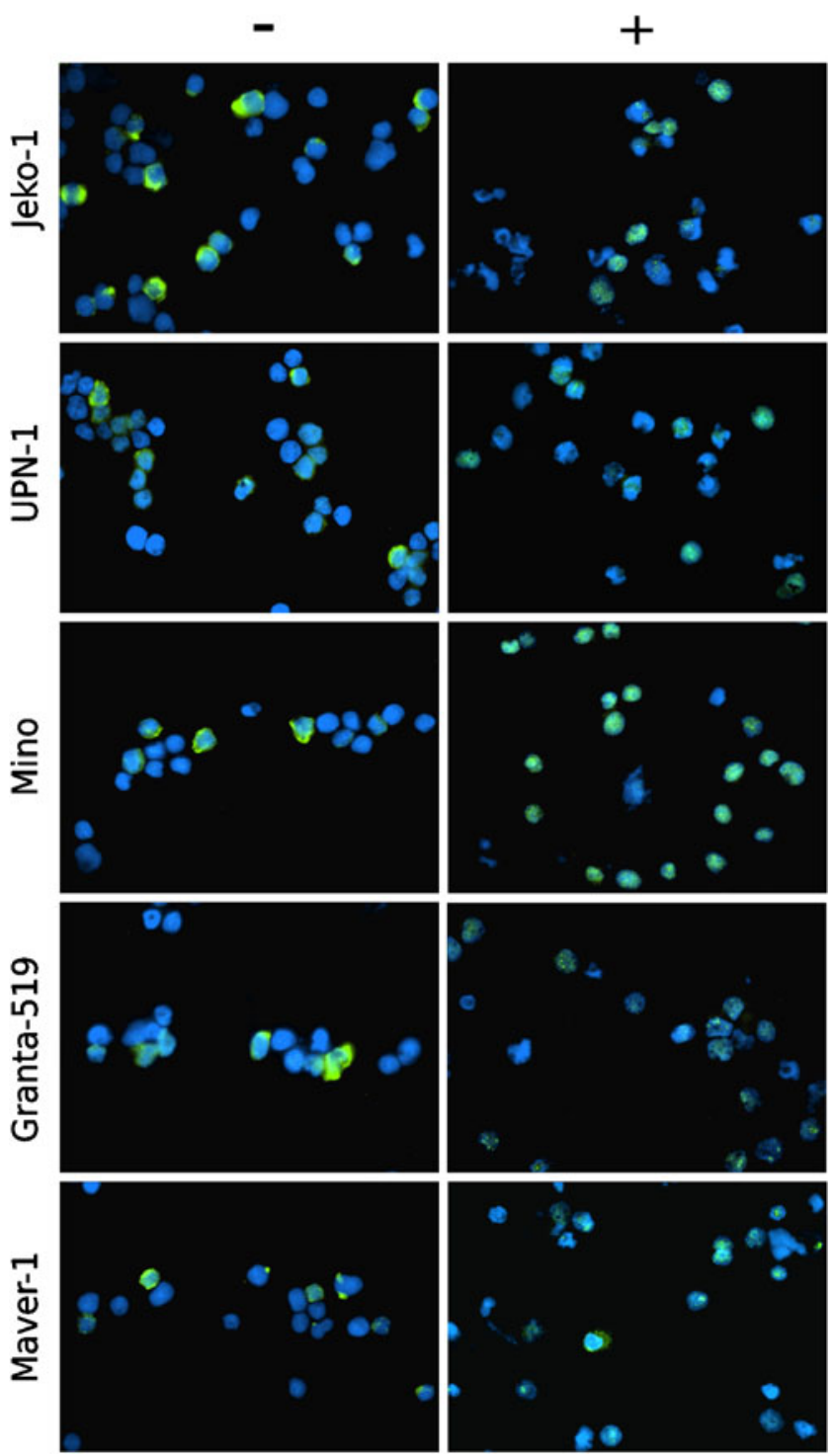

Fig. 7 Localization of phospho-Syk following piceatannol treatment. P-Syk Y525 (shown in green pseudo-color) disappears from the cytoplasm and appears in the nucleus after treatment in all cell lines. Nuclei counter stained in blue pseudo-color (DAPI staining)

lyzed by the Agilent 2100 Bioanalyzer and the DNA1000 Chip (Agilent Technologies).

Quantitative RT-PCR Quantitative RT-PCR mRNA expression analysis was performed on ABI PRISM 7900HT Fast Real-time PCR System (Applied Biosystems, Foster City, CA) using Power SYBR green PCR Master Mix (Applied Biosystems). Oligonucleotide primers used were: CCND1F AACTACCTGGACCGCTTCCT, and CCND1-R GGGGATGGTCTCCTTCATCT; TBP-F, GCACAG GAGCCAAGAGTGAA, and TBP-R, TCACAGCTCCC CACCATATT.
TATA box binding protein (RefSeq ID NM 003194.3) transcript level was used to normalize SYK expression.

Calibration curves for each couple of primers were obtained by serial dilution of cDNA. Expression data were analyzed by the comparative threshold cycle $(\mathrm{Ct})$ method accordingly to User Bulletin No. 2 (Applied Biosystems). All experiments were performed in triplicate. The statistical significance of the data was investigated by Student's $t$-test. All $\mathrm{P}$ values were two sided and considered significant when less than 0.05 .

Syk inhibition experiments Piceatannol (Sigma-Aldrich Chemie GmBH, Steinheim, Germany) was resuspendend in DMSO as a $100 \mathrm{mM}$ stock. Cells were diluted at $500 * 10^{3} / \mathrm{ml}$ in RPMI 1640 (1\% fetal calf serum) and let grow for $16 \mathrm{~h}$. Piceatannol was then added at concentrations between $1 \mu \mathrm{M}$ and $80 \mu \mathrm{M}$ (depending on the sensitivity of cell lines). Cells were harvested at 24 and $48 \mathrm{~h}$ and apoptosis levels analyzed by Annexin V (Annexin V-FITC apoptosis detection kit I, BD) as previously described [11]. All experiments were performed in triplicate.

Western blotting Immunoblotting was performed by standard methodology, using the antibodies and dilutions indicated Table 2. Protein content of samples was measured using a colorimetric method (DC protein assay, Bio-Rad). All lanes were loaded with the same amount of total protein (in duplicate or triplicate), and were also visually verified by Ponceau red staining after electroblotting.

Immunofluorescence Immunofluorescence was performed using the antibodies shown in Table 2 (both primary and secondary antibodies were diluted 1:100). Briefly, cells were washed in PBS, deposited on charged slides by gravity, fixed in cold methanol $\left(-20^{\circ} \mathrm{C}\right)$ for $20 \mathrm{~min}$ and then air-dried. Cells were then re-hydrated, incubated with protein blocking solution for $10^{\prime}$, then incubated serially with primary and secondary antibodies (with three washes in PBS in-between). Slides were examined under fluorescent light using an Olympus BX61 microscope. Images were acquired using appropriate filters via a monochromatic camera cooled CCD camera (iAi, Japan) and analyzed using the Olympus Cytovision software.

Acknowledgements Financially supported by AIRC MFAG grant to Alberto Zamò.

We would like to thank Roberto Polackiewitz from Cell Signaling Technology for helpful discussion.

Open Access This article is distributed under the terms of the Creative Commons Attribution Noncommercial License which permits any noncommercial use, distribution, and reproduction in any medium, provided the original author(s) and source are credited. 


\section{References}

1. S.H. Swerdlow, E. Campo, M. Seto, H.K. Muller-Hermelink, in Mantle cell lymphoma, in: WHO classification of tumours of haematopoietic and lymphoid tissues, ed. by S.H. Swerdlow, E. Campo, N.L. Harris, E.S. Jaffe, S. Pileri, H. Stein, J. Thiele, J. Vardiman (IARC Press, Lyon, 2008)

2. W.K. Hofmann, S. de Vos, K. Tsukasaki, W. Wachsman, G.S. Pinkus, J.W. Said, H.P. Koeffler, Altered apoptosis pathways in mantle cell lymphoma detected by oligonucleotide microarray. Blood 98, 787-794 (2001)

3. N. Martinez, F.I. Camacho, P. Algara, A. Rodriguez, A. Dopazo, E. Ruiz-Ballesteros, P. Martin, J.A. Martinez-Climent, J. Garcia-Conde, J. Menarguez, F. Solano, M. Mollejo, M.A. Piris, The molecular signature of mantle cell lymphoma reveals multiple signals favoring cell survival. Cancer Res. 63, 8226-8232 (2003)

4. E. Ortega-Paino, J. Fransson, S. Ek, C.A. Borrebaeck, Functionally associated targets in mantle cell lymphoma as defined by DNA microarrays and RNA interference. Blood 111, 1617-1624 (2008)

5. M. Pinyol, S. Bea, L. Pla, V. Ribrag, J. Bosq, A. Rosenwald, E. Campo, P. Jares, Inactivation of RB1 in mantle-cell lymphoma detected by nonsense-mediated mRNA decay pathway inhibition and microarray analysis. Blood 109, 5422-5429 (2007)

6. A. Rinaldi, I. Kwee, M. Taborelli, C. Largo, S. Uccella, V. Martin, G. Poretti, G. Gaidano, G. Calabrese, G. Martinelli, L. Baldini, G. Pruneri, C. Capella, E. Zucca, F.E. Cotter, J.C. Cigudosa, C.V. Catapano, M.G. Tibiletti, F. Bertoni, Genomic and expression profiling identifies the B-cell associated tyrosine kinase Syk as a possible therapeutic target in mantle cell lymphoma. Br. J. Haematol. 132, 303-316 (2006)

7. E.G. Rizzatti, R.P. Falcao, R.A. Panepucci, R. Proto-Siqueira, W. T. Anselmo-Lima, O.K. Okamoto, M.A. Zago, Gene expression profiling of mantle cell lymphoma cells reveals aberrant expression of genes from the PI3K-AKT, WNT and TGFbeta signalling pathways. Br. J. Haematol. 130, 516-526 (2005)

8. A. Rosenwald, G. Wright, A. Wiestner, W.C. Chan, J.M. Connors, E. Campo, R.D. Gascoyne, T.M. Grogan, H.K. Muller-Hermelink, E.B. Smeland, M. Chiorazzi, J.M. Giltnane, E.M. Hurt, H. Zhao, L. Averett, S. Henrickson, L. Yang, J. Powell, W.H. Wilson, E.S. Jaffe, R. Simon, R.D. Klausner, E. Montserrat, F. Bosch, T.C. Greiner, D.D. Weisenburger, W.G. Sanger, B.J. Dave, J.C. Lynch, J. Vose, J.O. Armitage, R.I. Fisher, T.P. Miller, M. LeBlanc, G. Ott, S. Kvaloy, H. Holte, J. Delabie, L.M. Staudt, The proliferation gene expression signature is a quantitative integrator of oncogenic events that predicts survival in mantle cell lymphoma. Cancer Cell 3, 185-197 (2003)

9. C. Thieblemont, V. Nasser, P. Felman, K. Leroy, S. Gazzo, E. Callet-Bauchu, B. Loriod, S. Granjeaud, P. Gaulard, C. Haioun, A. Traverse-Glehen, L. Baseggio, F. Bertucci, D. Birnbaum, F. Magrangeas, S. Minvielle, H. Avet-Loiseau, G. Salles, B. Coiffier, F. Berger, R. Houlgatte, Small lymphocytic lymphoma, marginal zone B-cell lymphoma, and mantle cell lymphoma exhibit distinct gene-expression profiles allowing molecular diagnosis. Blood 103, 2727-2737 (2004)

10. F. Antonucci, M. Chilosi, C. Parolini, M. Hamdan, H. Astner, P.G. Righetti, Two-dimensional molecular profiling of mantle cell lymphoma. Electrophoresis 24, 2376-2385 (2003)

11. D. Cecconi, A. Zamó, A. Parisi, E. Bianchi, C. Parolini, A.M. Timperio, L. Zolla, M. Chilosi, Induction of apoptosis in Jeko-1 mantle cell lymphoma cell line by resveratrol: a proteomic analysis. J. Proteome Res. 7, 2670-2680 (2008)

12. I.M. Ghobrial, D.J. McCormick, S.H. Kaufmann, A.A. Leontovich, D.A. Loegering, N.T. Dai, K.L. Krajnik, M.J. Stenson, M.F. Melhem, A.J. Novak, S.M. Ansell, T.E. Witzig, Proteomic analysis of mantle-cell lymphoma by protein microarray. Blood 105, 3722$3730(2005)$

13. M. Weinkauf, Y. Zimmermann, E. Hartmann, A. Rosenwald, M. Rieken, A. Pastore, G. Hutter, W. Hiddemann, M. Dreyling, 2-D PAGE-based comparison of proteasome inhibitor bortezomib in sensitive and resistant mantle cell lymphoma. Electrophoresis 30, 974-986 (2009)

14. C. Jansen, K.M. Hebeda, M. Linkels, J.M. Grefte, J.M. Raemaekers, J.H. van Krieken, P.J. Groenen, Protein profiling of B-cell lymphomas using tissue biopsies: a potential tool for small samples in pathology. Cell. Oncol. 30, 27-38 (2008)

15. C. Jansen, T. Feuth, J.M.M. Raemaekers, J. Rijntjes, J.W. Meijer, P.J. Westenend, J. van Baarlen, J.H.J.M. van Krieken, K.M. Hebeda, P.J.T.A. Groenen, Protein profiling in pathology: analysis and evaluation of 239 frozen tissue biopsies for diagnosis of Bcell lymphomas. Proteomics: Clin. Appl. 4, 519-527 (2010)

16. H. Stranneheim, L.M. Orre, J. Lehtio, J. Flygare, A comparison between protein profiles of B cell subpopulations and mantle cell lymphoma cells. Proteome Sci. 7, 43 (2009)

17. L. Miguet, G. Bechade, L. Fornecker, E. Zink, C. Felden, C. Gervais, R. Herbrecht, A. Van Dorsselaer, L. Mauvieux, S. Sanglier-Cianferani, Proteomic analysis of malignant B-cell derived microparticles reveals $\mathrm{CD} 148$ as a potentially useful antigenic biomarker for mantle cell lymphoma diagnosis. J. Proteome Res. 8, 3346-3354 (2009)

18. M. Weinkauf, M. Christopeit, W. Hiddemann, M. Dreyling, Proteome- and microarray-based expression analysis of lymphoma cell lines identifies a p53-centered cluster of differentially expressed proteins in mantle cell and follicular lymphoma. Electrophoresis 28, 4416-4426 (2007)

19. R.S. Boyd, R. Jukes-Jones, R. Walewska, D. Brown, M.J. Dyer, K. Cain, Protein profiling of plasma membranes defines aberrant signaling pathways in mantle cell lymphoma. Mol. Cell. Proteomics 8, 1501-1515 (2009)

20. D. Cecconi, A. Zamo, E. Bianchi, A. Parisi, S. Barbi, A. Milli, S. Rinalducci, A. Rosenwald, E. Hartmann, L. Zolla, M. Chilosi, Signal transduction pathways of mantle cell lymphoma: a phosphoproteome-based study. Proteomics 8, 4495-4506 (2008)

21. M. Weinkauf, W. Hiddemann, M. Dreyling, Sample pooling in 2D gel electrophoresis: a new approach to reduce nonspecific expression background. Electrophoresis 27, 4555-4558 (2006)

22. J. Rush, A. Moritz, K.A. Lee, A. Guo, V.L. Goss, E.J. Spek, H. Zhang, X.M. Zha, R.D. Polakiewicz, M.J. Comb, Immunoaffinity profiling of tyrosine phosphorylation in cancer cells. Nat. Biotechnol. 23, 94-101 (2005)

23. K. Rikova, A. Guo, Q. Zeng, A. Possemato, J. Yu, H. Haack, J. Nardone, K. Lee, C. Reeves, Y. Li, Y. Hu, Z. Tan, M. Stokes, L. Sullivan, J. Mitchell, R. Wetzel, J. Macneill, J.M. Ren, J. Yuan, C. E. Bakalarski, J. Villen, J.M. Kornhauser, B. Smith, D. Li, X. Zhou, S.P. Gygi, T.L. Gu, R.D. Polakiewicz, J. Rush, M.J. Comb, Global survey of phosphotyrosine signaling identifies oncogenic kinases in lung cancer. Cell 131, 1190-1203 (2007)

24. J. Carretero, T. Shimamura, K. Rikova, A.L. Jackson, M.D. Wilkerson, C.L. Borgman, M.S. Buttarazzi, B.A. Sanofsky, K.L. McNamara, K.A. Brandstetter, Z.E. Walton, T.L. Gu, J.C. Silva, K. Crosby, G.I. Shapiro, S.M. Maira, H. Ji, D.H. Castrillon, C.F. Kim, C. Garcia-Echeverria, N. Bardeesy, N.E. Sharpless, N.D. Hayes, W.Y. Kim, J.A. Engelman, K.K. Wong, Integrative genomic and proteomic analyses identify targets for Lkb1deficient metastatic lung tumors. Cancer Cell 17 547-559

25. D.K. Walters, V.L. Goss, E.P. Stoffregen, T.L. Gu, K. Lee, J. Nardone, L. McGreevey, M.C. Heinrich, M.W. Deininger, R. Polakiewicz, B.J. Druker, Phosphoproteomic analysis of AML cell lines identifies leukemic oncogenes. Leuk. Res. 30, 1097-1104 (2006)

26. V.L. Goss, K.A. Lee, A. Moritz, J. Nardone, E.J. Spek, J. MacNeill, J. Rush, M.J. Comb, R.D. Polakiewicz, A common 
phosphotyrosine signature for the Bcr-Abl kinase. Blood 107, 4888-4897 (2006)

27. T.L. Gu, V.L. Goss, C. Reeves, L. Popova, J. Nardone, J. Macneill, D.K. Walters, Y. Wang, J. Rush, M.J. Comb, B.J. Druker, R.D. Polakiewicz, Phosphotyrosine profiling identifies the KG-1 cell line as a model for the study of FGFR1 fusions in acute myeloid leukemia. Blood 108, 4202-4204 (2006)

28. T.L. Gu, J. Cherry, M. Tucker, J. Wu, C. Reeves, R.D. Polakiewicz, Identification of activated Tnk1 kinase in Hodgkin's lymphoma. Leukemia 24 861-865.

29. S. Bea, I. Salaverria, L. Armengol, M. Pinyol, V. Fernandez, E. M. Hartmann, P. Jares, V. Amador, L. Hernandez, A. Navarro, G. Ott, A. Rosenwald, X. Estivill, E. Campo, Uniparental disomies, homozygous deletions, amplifications, and target genes in mantle cell lymphoma revealed by integrative highresolution whole-genome profiling. Blood 113, 3059-3069 (2009)

30. F. Rubio-Moscardo, J. Climent, R. Siebert, M.A. Piris, J.I. MartinSubero, I. Nielander, J. Garcia-Conde, M.J. Dyer, M.J. Terol, D. Pinkel, J.A. Martinez-Climent, Mantle-cell lymphoma genotypes identified with $\mathrm{CGH}$ to BAC microarrays define a leukemic subgroup of disease and predict patient outcome. Blood 105, 4445-4454 (2005)

31. I. Vater, F. Wagner, M. Kreuz, H. Berger, J.I. Martin-Subero, C. Pott, J.A. Martinez-Climent, W. Klapper, K. Krause, M.J. Dyer, S. Gesk, L. Harder, A. Zamo, M. Dreyling, D. Hasenclever, N. Arnold, R. Siebert, GeneChip analyses point to novel pathogenetic mechanisms in mantle cell lymphoma. Br. J. Haematol. 144, 317-331 (2009)

32. D. Hui, T. Reiman, J. Hanson, R. Linford, W. Wong, A. Belch, R. Lai, Immunohistochemical detection of cdc2 is useful in predicting survival in patients with mantle cell lymphoma. Mod. Pathol. 18, 1223-1231 (2005)

33. F. Jardin, J.M. Picquenot, F. Parmentier, P. Ruminy, M. Cornic, D. Penther, P. Bertrand, H. Lanic, O. Cassuto, C. Humbrecht, E. Lemasle, A. Wautier, C. Bastard, H. Tilly, Detection of gene copy number aberrations in mantle cell lymphoma by a single quantitative multiplex PCR assay: clinicopathological relevance and prognosis value. Br. J. Haematol. (2009)

34. H. Tagawa, S. Karnan, R. Suzuki, K. Matsuo, X. Zhang, A. Ota, Y. Morishima, S. Nakamura, M. Seto, Genome-wide array-based CGH for mantle cell lymphoma: identification of homozygous deletions of the proapoptotic gene. BIM Oncogene 24, 1348-1358 (2005)

35. Y.Y. Cho, F. Tang, K. Yao, C. Lu, F. Zhu, D. Zheng, A. Pugliese, A.M. Bode, Z. Dong, Cyclin-dependent kinase-3-mediated c-Jun phosphorylation at Ser63 and Ser73 enhances cell transformation. Cancer Res. 69, 272-281 (2009)

36. D. Zheng, Y.Y. Cho, A.T. Lau, J. Zhang, W.Y. Ma, A.M. Bode, Z. Dong, Cyclin-dependent kinase 3-mediated activating transcription factor 1 phosphorylation enhances cell transformation. Cancer Res. 68, 7650-7660 (2008)

37. H. Ogata, S. Goto, K. Sato, W. Fujibuchi, H. Bono, M. Kanehisa, KEGG: Kyoto Encyclopedia of Genes and Genomes. Nucleic Acids Res. 27, 29-34 (1999)

38. L. Chen, S. Monti, P. Juszczynski, J. Daley, W. Chen, T.E. Witzig, T.M. Habermann, J.L. Kutok, M.A. Shipp, SYK-dependent tonic $\mathrm{B}$-cell receptor signaling is a rational treatment target in diffuse large B-cell lymphoma. Blood 111, 2230-2237 (2008)

39. R.E. Davis, V.N. Ngo, G. Lenz, P. Tolar, R.M. Young, P.B. Romesser, H. Kohlhammer, L. Lamy, H. Zhao, Y. Yang, W. Xu, A.L. Shaffer, G. Wright, W. Xiao, J. Powell, J.K. Jiang, C.J. Thomas, A. Rosenwald, G. Ott, H.K. Muller-Hermelink, R.D. Gascoyne, J.M. Connors, N.A. Johnson, L.M. Rimsza, E. Campo, E.S. Jaffe, W.H. Wilson, J. Delabie, E.B. Smeland, R.I. Fisher, R. M. Braziel, R.R. Tubbs, J.R. Cook, D.D. Weisenburger, W.C.
Chan, S.K. Pierce, L.M. Staudt, Chronic active B-cell-receptor signalling in diffuse large B-cell lymphoma. Nature 463 88-92

40. S. Gobessi, L. Laurenti, P.G. Longo, L. Carsetti, V. Berno, S. Sica, G. Leone, D.G. Efremov, Inhibition of constitutive and BCR-induced Syk activation downregulates Mcl-1 and induces apoptosis in chronic lymphocytic leukemia B cells. Leukemia 23, 686-697 (2009)

41. J.W. Friedberg, J. Sharman, J. Sweetenham, P.B. Johnston, J.M. Vose, A. Lacasce, J. Schaefer-Cutillo, S. De Vos, R. Sinha, J.P. Leonard, L.D. Cripe, S.A. Gregory, M.P. Sterba, A.M. Lowe, R. Levy, M.A. Shipp, Inhibition of Syk with fostamatinib disodium has significant clinical activity in non-Hodgkin lymphoma and chronic lymphocytic leukemia. Blood 115 2578-2585

42. J.M. Oliver, D.L. Burg, B.S. Wilson, J.L. McLaughlin, R.L. Geahlen, Inhibition of mast cell Fc epsilon R1-mediated signaling and effector function by the Syk-selective inhibitor, piceatannol. J. Biol. Chem. 269, 29697-29703 (1994)

43. L. Leseux, S.M. Hamdi, T. Al Saati, F. Capilla, C. Recher, G. Laurent, C. Bezombes, Syk-dependent mTOR activation in follicular lymphoma cells. Blood 108, 4156-4162 (2006)

44. A. Rinaldi, I. Kwee, M. Taborelli, C. Largo, S. Uccella, V. Martin, G. Poretti, G. Gaidano, G. Calabrese, G. Martinelli, L. Baldini, G. Pruneri, C. Capella, E. Zucca, F.E. Cotter, J.C. Cigudosa, C.V. Catapano, M.G. Tibiletti, F. Bertoni, Genomic and expression profiling identifies the B-cell associated tyrosine kinase Syk as a possible therapeutic target in mantle cell lymphoma. Br. J. Haematol. 132, 303-316 (2006)

45. J. Ennaciri, D. Girard, IL-4R(alpha), a new member that associates with Syk kinase: implication in IL-4-induced human neutrophil functions. J. Immunol. 183, 5261-5269 (2009)

46. L. Wang, E. Devarajan, J. He, S.P. Reddy, J.L. Dai, Transcription repressor activity of spleen tyrosine kinase mediates breast tumor suppression. Cancer Res. 65, 10289-10297 (2005)

47. F.M. Uckun, S. Qazi, H. Ma, L. Tuel-Ahlgren, Z. Ozer, STAT3 is a substrate of SYK tyrosine kinase in B-lineage leukemia/ lymphoma cells exposed to oxidative stress. Proc. Natl. Acad. Sci. U S A 107 2902-2907.

48. F. Baran-Marszak, M. Boukhiar, S. Harel, C. Laguillier, C. Roger, R. Gressin, A. Martin, R. Fagard, N. Varin-Blank, F. AjchenbaumCymbalista, D. Ledoux, Constitutive and B-cell receptor-induced activation of STAT3 are important signaling pathways targeted by bortezomib in leukemic mantle cell lymphoma. Haematologica 95, 1865-1872 (2010)

49. L.V. Pham, A.T. Tamayo, C. Li, W. Bornmann, W. Priebe, R.J. Ford, Degrasyn potentiates the antitumor effects of bortezomib in mantle cell lymphoma cells in vitro and in vivo: therapeutic implications. Mol. Cancer Ther. 9, 2026-2036 (2010)

50. S. Tauzin, H. Ding, K. Khatib, I. Ahmad, D. Burdevet, G. van Echten-Deckert, J.A. Lindquist, B. Schraven, N.U. Din, B. Borisch, D.C. Hoessli, Oncogenic association of the Cbp/PAG adaptor protein with the Lyn tyrosine kinase in human B-NHL rafts. Blood 111, 2310-2320 (2008)

51. M.A. Yared, J.D. Khoury, L.J. Medeiros, G.Z. Rassidakis, R. Lai, Activation status of the JAK/STAT3 pathway in mantle cell lymphoma. Arch. Pathol. Lab. Med. 129, 990-996 (2005)

52. R. Lai, G.Z. Rassidakis, L.J. Medeiros, V. Leventaki, M. Keating, T.J. McDonnell, Expression of STAT3 and its phosphorylated forms in mantle cell lymphoma cell lines and tumours. J. Pathol. 199, 84-89 (2003)

53. J.A. Diehl, M. Cheng, M.F. Roussel, C.J. Sherr, Glycogen synthase kinase-3beta regulates cyclin D1 proteolysis and subcellular localization. Genes Dev. 12, 3499-3511 (1998)

54. J. Camps, I. Salaverria, M.J. Garcia, E. Prat, S. Bea, J.C. Pole, L. Hernandez, J. Del Rey, J.C. Cigudosa, M. Bernues, C. Caldas, D. Colomer, R. Miro, E. Campo, Genomic imbalances and patterns of karyotypic variability in mantle-cell lymphoma cell lines. Leuk. Res. 30, 923-934 (2006) 
55. S.W. Tait, D.R. Green, Mitochondria and cell death: outer membrane permeabilization and beyond. Nat. Rev. Mol. Cell Biol. 11, 621-632 (2010)

56. T. Miyashita, J.C. Reed, Tumor suppressor p53 is a direct transcriptional activator of the human bax gene. Cell 80, 293299 (1995)

57. F. Zhou, J. Hu, H. Ma, M.L. Harrison, R.L. Geahlen, Nucleocytoplasmic trafficking of the Syk protein tyrosine kinase. Mol. Cell. Biol. 26, 3478-3491 (2006)

58. L. Wang, L. Duke, P.S. Zhang, R.B. Arlinghaus, W.F. Symmans, A. Sahin, R. Mendez, J.L. Dai, Alternative splicing disrupts a nuclear localization signal in spleen tyrosine kinase that is required for invasion suppression in breast cancer. Cancer Res. 63, 4724- 4730 (2003)
59. L. Bordin, C. Fiore, M. Bragadin, A.M. Brunati, G. Clari, Regulation of membrane band 3 Tyr-phosphorylation by proteolysis of p72(Syk) and possible involvement in senescence process. Acta. Biochim. Biophys. Sin. (Shanghai) 41, 846-851 (2009)

60. A. Zamo, G. Ott, T. Katzenberger, P. Adam, C. Parolini, A. Scarpa, M. Lestani, F. Menestrina, M. Chilosi, Establishment of the MAVER1 cell line, a model for leukemic and aggressive mantle cell lymphoma. Haematologica 91, 40-47 (2006)

61. G. Dennis Jr., B.T. Sherman, D.A. Hosack, J. Yang, W. Gao, H.C. Lane, R.A. Lempicki, DAVID: Database for Annotation, Visualization, and Integrated Discovery. Genome Biol. 4, P3 (2003) 